Methods The intervention has been implemented in four areas, with two control areas. Quantitative and qualitative methods were used in the evaluation, including a household survey, focus groups and questionnaires, administered to parents, children and service providers. Observation visits were made to randomly selected Creches and SwimSafe centres.

Results 44 out of 45 Community creches were operating when the observation visit took place and were functioning well. The creches were accepted by the local community, with evidence of untapped demand for places. Observations on SwimSafe centres showed that $23 / 30$ were operating on the day of the visit and were functioning properly. Physical facilities like landing places and swimming platforms were found to be satisfactory. Most of the swimming graduates reportedly had acquired the standard swimming skills (93\%) and knowledge of rescue techniques $(95 \%)$.

Conclusion The interventions were acceptable to the local community, implemented in the manner for which they were designed and contributed to knowledge change, observed and reported behaviour change and modifications to the environment. Tackling unintentional injuries requires coordinated action across health and other sectors, with strong community involvement to enhance sustainability.

\section{INDEPENDENT EVALUATION OF THE PREVENTION OF CHILD INJURIES THROUGH SOCIAL-INTERVENTION AND EDUCATION (PRECISE) PROGRAMME IN BANGLADESH}

E Towner*, M Shuaib, S Shafinaz Correspondence: Centre for Child and Adolescent Health, University of the West of England, Bristol, Hampton House, Cotham Hill, Bristol BS6 6JS, UK

\subsection{6/ip.2010.029215.834}

Aim To evaluate the implementation and acceptability of the PRECISE child injury project in Bangladesh.

Background Each year in Bangladesh, 30000 children die from unintentional injuries; drowning is the single leading cause of death in children aged 1-17 years. PRECISE is a community-based project with many interrelated components, including Community crche and SwimSafe programmes, tailored to the Bangladesh environment. 